\title{
ANÁLISE TERMOGRAVIMÉTRICA DA CARTILAGEM ARTICULAR DE RATOS EXERCITADOS APÓS IMOBILIZAÇÃO
}

\author{
THERMOGRAVIMETRIC ANALYSIS OF ARTICULAR CARTILAGE OF EXERCISED RATS \\ AFTER IMMOBILIZATION
}

\section{ANÁLISIS TERMOGRAVIMÉTRICO DEL CARTÍLAGO ARTICULAR DE RATONES EJERCITADOS DESPUÉS DE INMOVILIZACIÓN}

\author{
Guilherme Akio Tamura Ozaki ${ }^{1}$ \\ (Fisioterapeuta) \\ Fábio Yoshikazu Kodama² \\ (Fisioterapeuta) \\ Regina Celi Trindade Camargo \\ (Fisioterapeuta) \\ Aldo Eloizo Job \\ (Licenciatura em Ciências) \\ Tatiana Emy Koike ${ }^{1}$ (Fisioterapeuta) \\ Adriana Yukie Watanabe ${ }^{2}$ \\ (Fisioterapeuta) \\ José Carlos Silva Camargo Filho ${ }^{1}$ \\ (Fisioterapeuta) \\ 1. Universidade Estadual Paulista \\ "Júlio de Mesquita Filho" \\ (FCT/UNESP), Faculdade de Ciências \\ e Tecnologia, Presidente Prudente, \\ SP, Brasil. \\ 2. Universidade Paulista (UNIP), \\ Araçatuba, SP, Brasil.
}

\section{Correspondência:}

Departamento de Fisioterapia

- FCT/UNESP, Laboratório de Histologia e Histoquímica. Rua Roberto Simonsen, 305, Presidente Prudente, SP, Brasil. 19060-900.

guiozaki@hotmail.com

\section{RESUMO}

Introdução: A imobilização articular é uma técnica de tratamento frequentemente utilizada na ortopedia e, associada ao processo de senescência, promove alterações tanto na estrutura quanto na síntese e biomecânica do tecido cartilaginoso. Objetivo: Descrever os efeitos da imobilização, da remobilização livre e por meio de exercício físico sobre a cartilagem articular de ratos situados em duas faixas etárias. Métodos: Trinta e nove ratos Wistar divididos em dois grupos etários, um grupo adulto (cinco meses de idade) e um idoso (15 meses de idade), subdivididos em: controle, imobilizado, remobilizado livre e remobilizado por meio de exercício físico. Os membros posteriores dos ratos foram imobilizados por sete dias. O protocolo de exercícios foi composto por cinco sessões diárias de natação, de 25 minutos cada. A cartilagem articular do quadril foi submetida à análise termogravimétrica, tendo sido avaliado seu conteúdo de água. Resultados: Nos animais adultos a imobilização reduziu a quantidade de água presente no tecido cartilaginoso, e os protocolos de remobilização foram eficazes para restabelecer a condição inicial do tecido. Nos animais idosos não houve diferença significativa entre os grupos, porém o grupo idoso controle obteve resultado significantemente menor que o grupo adulto controle (X: 13,10 \pm 5,24 vs 10,70 \pm 1,95). Conclusões: A imobilização e o processo de senescência induzem a diminuição do conteúdo de água da cartilagem articular e os protocolos de remobilização foram eficientes para restabelecer esta propriedade apenas nos animais adultos.

Palavras-chave: natação, termogravimetria, fatores etários.

\section{ABSTRACT}

Introduction: Joint immobilization is a technique often used in orthopedic treatment and, associated with the aging process, promotes changes in both the structure and synthesis and biomechanics of cartilage tissue. Objective: To describe the effects of immobilization, free remobilization and remobilization by physical exercise over articular cartilage of rats of two age groups. Methods: Thirty nine Wistar rats divided into two groups according to age, an adult group (five months old) and an elderly group (15 months old), and subdivided into: control, immobilized, free remobilized and remobilized by physical exercise. The pelvic limb of rats was immobilized for seven days. The exercise protocol consisted of 25 minutes swimming sessions, five sessions per day. The hip articular cartilage was subjected to thermogravimetric analysis, and the water content was evaluated. Results: In adult animals immobilization reduced the water content of the articular cartilage, and the remobilization protocols were effective to restore the initial condition of the tissue. In elderly animals there were not significant differences among the groups, however the elderly control group obtained results significantly lower than the adult control group (X:13.10 \pm 5.24 vs 10.70 \pm 1.95 ). Conclusions: Immobilization and the senescence process induce the decrease of water content of articular cartilage and remobilization protocols were effective to restoring this property only in adult animals.

Keywords: swimming, thermogravimetry, age factors.

\section{RESUMEN}

Introducción: La inmovilización articular es una técnica de tratamiento frecuentemente utilizada en ortopedia y asociada al proceso de senescencia, que promueve alteraciones tanto en la estructura como en la síntesis y la biomecánica del tejido cartilaginoso. Objetivo: Describir los efectos de la inmovilización, de la removilización libre y mediante el ejercicio físico sobre el cartílago articular de ratones de dos grupos de edad. Métodos: Treinta y nueve ratones Wistar divididos en dos grupos de edad, un grupo adulto (cinco meses) y un grupo anciano (15 meses), y subdividos en control, inmovilizado, removilizado libre y removilizado a través de ejercicio físico. Los miembros posteriores de los ratones fueron inmovilizados durante un período de siete días. El protocolo de ejercicios fue compuesto por cinco sesiones diarias de natación, de 25 minutos cada una. El cartílago articular de la cadera fue sometido a análisis termogravimétrico, siendo evaluado su contenido de agua. Resultados: En los animales adultos la inmovilización redujo la cantidad de agua presente en el tejido cartilaginoso, y los protocolos 
de removilización fueron eficaces para restablecer la condición inicial del tejido. En los animales ancianos no hubo diferencia significativa entre los grupos, aunque el grupo anciano control obtuvo resultado significativamente menor que el grupo adulto control ( $X: 13,10 \pm 5,24$ vs 10,70 $\pm 1,95)$. Conclusiones: La inmovilización y el proceso de senescencia inducen la disminución en el contenido de agua de cartílago articular y los protocolos de removilización fueron eficientes para restablecer esta propiedad sólo en los animales adultos.

Palabras clave: natación, termogravimetría, factores de edad.

\section{INTRODUÇÃO}

A imobilização articular é uma técnica de tratamento frequentemente utilizada na ortopedia para redução da dor e danos articulares ${ }^{1}$, que pode incorrer em alterações desfavoráveis como contraturas, osteoporose periarticular, e degeneração da cartilagem. Segundo Narmoneva et al. ${ }^{2}$, tal estrutura necessita de algum regime de carga e movimento para manter sua natureza física e propriedades bioquímicas.

A cartilagem articular é composta por dois componentes principais: uma matriz extracelular, e os condrócitos. A matriz extracelular é composta principalmente por um arcabouço de proteoglicanos, os agrecanos, e colágeno, predominantemente tipo $\|^{3}$. Esses componentes são sintetizados pelos condrócitos, tipo celular único e característico desse tecido. Outra característica desse tecido é o fato de ser avascular, sendo nutrida pelos capilares do tecido conjuntivo envolvente (pericôndrio) ou através do líquido sinovial das cavidades articulares. Além disso, é um tecido altamente hidratado, sendo essa hidratação dependente primariamente da grande concentração de cargas negativas presentes nos grupos carboxila e sulfato dos proteoglicanos, que atrai íons positivos, como o sódio, e repele íons negativos, como o cloro, aumentando assim a osmolaridade do tecido 4 .

Por ser um tecido avascular, a água apresenta um papel fundamental no metabolismo da cartilagem articular, pois é por meio dela que ocorre a entrada de nutrientes e eliminação de catabólicos ${ }^{5}$. A quantidade de água do tecido cartilaginoso quando submetida à imobilização e ao processo de senescência foi pouco estudado apesar da importância deste componente, tanto na estrutura quanto na síntese e biomecânica deste tecido. Além disso, a água atua no tecido cartilaginoso conferindo turgidez à matriz, tendo papel importante na absorção de impactos, juntamente com as fibras estruturais da cartilagem ${ }^{6,7}$.

A análise termogravimétrica se baseia no estudo da variação da massa da amostra em função da temperatura. Nela a perda de massa é medida continuamente, durante um aumento constante da temperatura ${ }^{8}$. Quando associada ao espectrofotômetro, essa análise permite a avaliação dos elementos químicos liberados durante o aquecimento ${ }^{9}$.

Desta forma, o estudo dos processos envolvidos na reparação ou regeneração, é de fundamental importância, inclusive para fundamentar possíveis intervenções que poderiam postergar ou minimizar a história natural da degeneração da cartilagem articular. Assim, este estudo foi delineado a fim de analisar os efeitos da remobilização por meio de exercício físico sobre o tecido cartilaginoso de ratos adultos e idosos após imobilização.

\section{MATERIAL E MÉTODO}

Foram utilizados 39 ratos machos da linhagem Wistar (Rattus novergicus, variedade albina, Rodentia, Mammalia) fornecidos pelo Biotério Central da Universidade Estadual Paulista (UNESP) - Campus de Botucatu, SP, Brasil, que foram mantidos no Biotério do Laboratório de Histologia e Histoquímica da Faculdade de Ciências e Tecnologia - FCT/UNESP, de Presidente Prudente, SP, Brasil, em gaiolas plásticas coletivas (30×16×19 cm), com no máximo cinco animais em cada gaiola, sob temperatura média de $22 \pm 2 C^{\circ}$, umidade relativa a 50\% \pm 10 , ciclo claro/escuro de 12 horas (7-19h), alimentação padrão e água fornecidos ad libitum.

Todos os procedimentos adotados foram aprovados pelo Comitê de Ética no Uso de Animais (CEUA) da Faculdade de Ciências e Tecnologia de Presidente Prudente (FCT/UNESP) sob protocolo n 05/2010.

Os animais foram divididos em dois grupos de acordo com a faixa etária, um grupo adulto (cinco meses) e um grupo idoso (15 meses), e subdividido em quatro grupos experimentais:

- Grupo Adulto Controle (GAC, $n=$ cinco) e Grupo Idoso Controle ( $G / d C, n=c i n c o)$. Animais que permaneceram no biotério durante o período experimental e foram eutanasiados de forma pareada com os grupos remobilizados;

- Grupo Adulto Imobilizado (GAl, $n=q u a t r o)$ e Grupo Idoso Imobilizado (Gldl, $n=$ cinco). Animais que foram submetidos à imobilização gessada, sendo eutanasiados logo após a retirada da mesma;

- Grupo Adulto Remobilizado Livre (GARL, $n=$ cinco) e Grupo Idoso Remobilizado Livre (GIdRL, $n=$ cinco). Animais que foram submetidos à imobilização gessada, seguida de remobilização, sendo posteriormente eutanasiados;

- Grupo Adulto Remobilizado por meio de Exercício físico (GARE, $n=$ cinco) e Idoso remobilizado por meio de exercício físico (GIdRE, $n=c i n c o)$. Animais que foram submetidos à imobilização gessada seguida de dois dias de remobilização livre e exercício físico de natação por período de cinco dias, sendo posteriormente eutanasiados.

Para aplicação da técnica de imobilização os animais foram anestesiados com cloridrato de ketamina $(80 \mathrm{mg} / \mathrm{kg}$ ) e cloridrato de xilazina $(15 \mathrm{mg} / \mathrm{kg})$ via intraperitoneal ${ }^{10}$, e uma vez anestesiados, os tornozelos dos animais foram envolvidos por uma malha tubular sendo em seguida imobilizados por meio de atadura gessada de secagem rápida com aproximadamente três centímetros de largura, desde a pelve até o tornozelo (figura 1). Os membros posteriores dos animais foram mantidos em posição de extensão quadril e joelho, e flexão plantar de tornozelo.

Os animais permaneceram imobilizados por sete dias consecuti$\operatorname{vos}^{11,12}$ e foram mantidos em gaiolas individuais com livre acesso a água e ração. Sempre que necessário o gesso foi substituído, respeitando o mesmo procedimento.

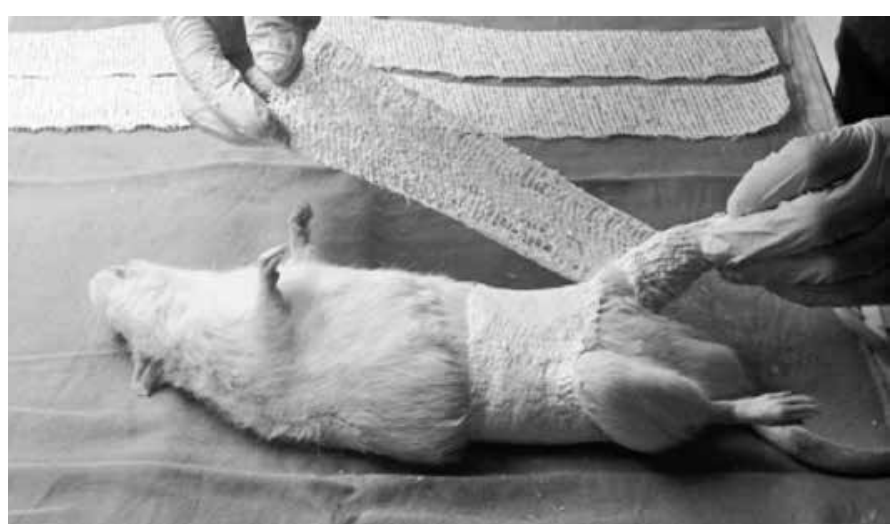

Figura 1. Aplicação da técnica de imobilização gessada. 
Os animais dos grupos GARL e GIdRL após a retirada da imobilização foram colocados em gaiolas coletivas para a remobilização livre, permanecendo no biotério por sete dias, sendo eutanasiados após esse procedimento.

Os animais dos grupos GARE e GIdRE também foram submetidos ao mesmo procedimento, porém por período de dois dias, antes da aplicação do protocolo de exercício físico.

O protocolo de exercício físico foi precedido da adaptação ao meio líquido. A adaptação ocorreu em um tanque cilíndrico com superfície lisa, medindo $30 \mathrm{~cm}$ de diâmetro por $120 \mathrm{~cm}$ de profundidade, com a temperatura da água mantida a $31 \pm 1^{\circ} \mathrm{C}$, nível da água a $10 \mathrm{~cm}$ por três dias consecutivos e duração de 15 min. O propósito da adaptação foi reduzir o estresse do animal sem, entretanto, promover adaptações fisiológicas decorrentes do treinamento físico.

\section{Protocolo de exercício físico}

Após dois dias de remobilização livre, os animais dos grupos GARE e GldRE foram submetidos a cinco sessões diárias de natação em um tanque medindo $120 \mathrm{~cm}$ de diâmetro x $75 \mathrm{~cm}$ de altura, divididos em oito compartimentos cilíndricos individuais de PVC (30 cm de diâmetro x $120 \mathrm{~cm}$ de altura) contendo água a $70 \mathrm{~cm}$ de profundidade com temperatura de $31 \pm 1^{\circ} \mathrm{C}$. O exercício foi realizado sem carga e com duração de 25 min.

A eutanásia foi realizada por administração intraperitoneal de uma dose excessiva de cloridrato de ketamina e cloridrato de xilazina via intraperitoneal, seguindo os princípios éticos em pesquisa animal.

O membro pélvico direito foi retirado de todos os animais por meio de desarticulação do quadril. Foram dissecados os músculos da região anterior e posterior do quadril, expondo a articulação. A cápsula foi aberta, o ligamento redondo da cabeça do fêmur foi seccionado e a cabeça femoral foi separada e isolada por meio de uma secção da porção distal do colo do fêmur.

A cabeça do fêmur direito dos animais foi armazenada em solução fisiológica de cloreto de sódio a 0,9\% e congelada. Posteriormente foi descongelado e retirado um pequeno fragmento de cartilagem articular ( $\pm 5 \mathrm{mg}$ ) com o mínimo de tecido ósseo para a análise termogravimétrica.

\section{Análise termogravimétrica (TGA)}

Para análise da cartilagem foi utilizado o equipamento da marca NETZSCH modelo 209, na faixa de temperatura ambiente até $180^{\circ} \mathrm{C}$, com uma taxa de aquecimento de $10^{\circ} \mathrm{C}$ por minuto.

A análise foi realizada colocando um fragmento de cartilagem com peso de aproximadamente $5 \mathrm{mg}$ em um pequeno recipiente de alumina, acoplada a uma balança de precisão em atmosfera de nitrogênio. Esse fragmento foi obtido da região central da superfície articular com o mínimo de tecido ósseo possível e, foi submetido à variação progressiva e constante de temperatura $\left({ }^{\circ} \mathrm{C}\right)$, registrando-se a perda da massa (mg) durante todo o processo de aquecimento. Os produtos voláteis liberados pelo aquecimento foram analisados quanto à sua composição e ligações químicas, em função da deformação do feixe de radiação infravermelho emitido contra essas substâncias voláteis e registrado em uma curva de absorbância pelo número de ondas.

\section{Análise estatística}

Para análise estatística foi utilizado o programa estatístico SPSS 17.0 for Windows. Foi aplicado o teste de normalidade de Shapiro-Wilk para verificar a presença ou ausência de distribuição Gaussiana. Para verificação de diferenças entre as variáveis dos diferentes grupos, adulto e idoso, foi utilizada a análise de variância (ANOVA - One Way) e pós teste de Tukey. Para estabelecer a comparação entre os grupos adulto e idoso, foi utilizado o teste $t$ de student para amostras independentes. Para todas as análises, o nível de significância adotado foi de $5 \%(<0,05)$.

\section{RESULTADOS}

Os gráficos da análise termogravimétrica e dos produtos voláteis liberados durante o aquecimento são apresentados nas figuras 2 e 3 . A figura 2 demonstra a perda progressiva de massa durante o aquecimento da amostra, e a figura 3 da análise dos produtos voláteis apresenta absorção de ondas na faixa entre $3960-3480 \mathrm{~cm}^{-1}$ e $1950-1300 \mathrm{~cm}^{-1}$, evidenciando que houve apenas perda de água durante o experimento.

Os resultados da análise termogravimétrica estão demonstrados na tabela 1, ratos adultos, e na tabela 2, ratos idosos. Nota-se que há diferença significativa entre o grupo GAC e GAl. Há também diferença significativa entre os grupos controle adulto e idoso (figura 4).

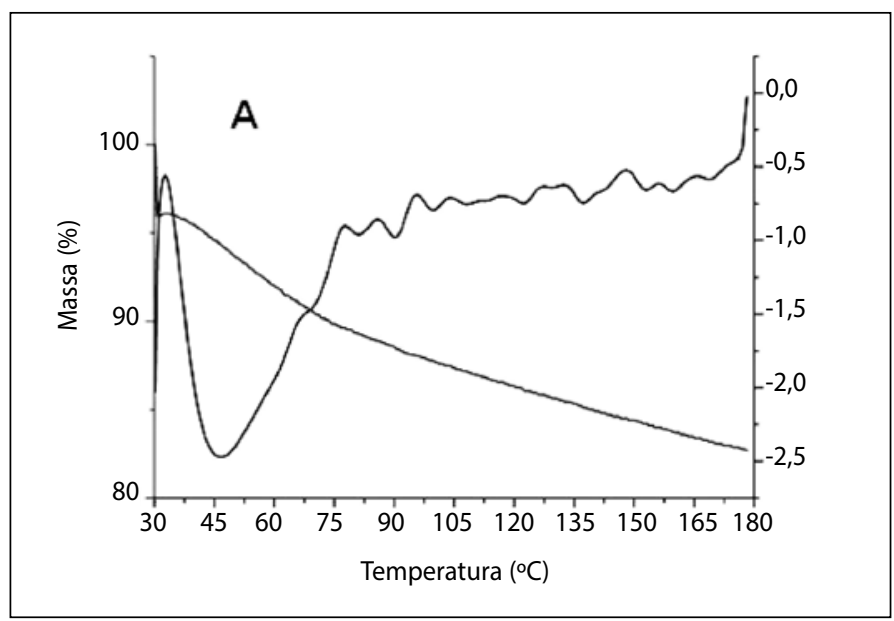

Figura 2. Variação da massa (\%) em relação a temperatura $\left({ }^{\circ} \mathrm{C}\right)$, e a derivada da curva (\%/min) de um animal do GAC.

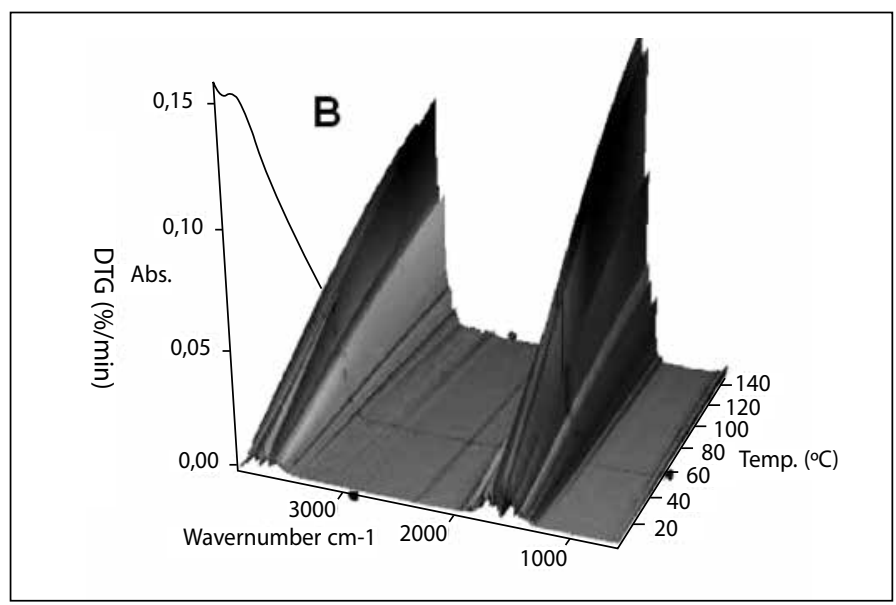

Figura 3. Análise do espectrofotômetro de um animal do GAl, nota-se o picos de absorbância de ondas na faixa entre 3960-3480 cm-1 e 1950-1300 cm-1, que evidenciam que houve apenas vapor de água liberado durante o experimento. $\mathrm{A} 60^{\circ} \mathrm{C}$ de temperatura ocorreu à maior perda de massa da amostra.

Tabela 1. Valores de médias e respectivos desvios-padrão referentes a \% de perda de água cartilagem articular dos ratos adultos.

\begin{tabular}{c|c}
\hline Grupos & \% de perda de água \\
\hline GAC & $22,00 \pm 4,26$ \\
\hline GAl & $14,06 \pm 3,57^{\mathrm{a}}$ \\
\hline GARL & $17,73 \pm 1,79$ \\
\hline GARE & $18,89 \pm 3,46$ \\
\hline
\end{tabular}

a $<<0,05$ (comparado com GAC); GAC = Adulto controle; GAI = Adulto Imobilizado; GARL = Remobilizado livre e GARE = Remobilizado por meio de exercício físico. 
Tabela 2. Valores de médias e respectivos desvios-padrão referentes a \% de água cartilagem articular dos ratos idosos.

\begin{tabular}{c|c}
\hline Grupos & \% de perda de água \\
\hline GldC & $13,10 \pm 5,24$ \\
\hline Gldl & $9,53 \pm 2,23$ \\
\hline GldRL & $11,48 \pm 4,86$ \\
\hline GldRE & $10,70 \pm 1,95$ \\
\hline
\end{tabular}

GldC = Idoso controle; Gld = Imobilizado; GIdRL = Remobilizado livre e GldRE = Remobilizado por meio de exercício físico.

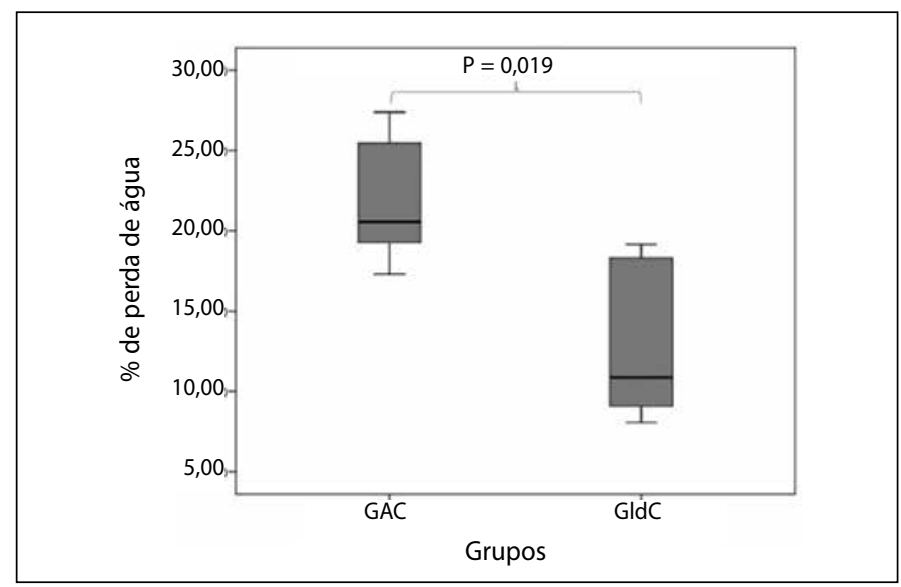

Figura 4. Box-plot comparando os resultados dos grupos GAC e GldC, evidenciando que houve diferença significante entre os grupos.

\section{DISCUSSÃO}

No presente estudo o gráfico da análise dos produtos voláteis liberados durante o aquecimento da cartilagem confirma que somente apenas a água foi liberada durante o experimento, sendo assim, toda a perda de massa durante a análise se deve a sua evaporação. Estudos realizados com tecido cartilaginoso de ratos $^{9}$ e de humanos ${ }^{5}$ também obtiveram o mesmo achado, com o aquecimento do tecido até $150^{\circ} \mathrm{C}$.

O conteúdo de água do tecido cartilaginoso dos animais imobilizados (GAl) teve diminuição significativa, em comparação com os animais do grupo controle (GAC). Quando submetido à imobilização articular, o tecido cartilaginoso sofre perda de proteoglicanas, massa e volume total da cartilagem ${ }^{7,13}$. Essas alterações afetam diretamente a capacidade mecânica da cartilagem articular, pois sua integridade estrutural é fundamental para seu desempenho funcional.

A perda da quantidade de água pelo tecido cartilaginoso dificulta o metabolismo dos condrócitos, uma vez que, por ser avascular, a nutrição do tecido e a retirada dos catabólicos provenientes do processo metabólico, são realizadas por difusão por meio do líquido contido na matriz extracelular ${ }^{5}$. As alterações catabólicas induzidas pela imobilização resultar também em perda de proteoglicanas ${ }^{14}$.

As proteoglicanas são compostas por um centro proteico associado a glicosaminoglicanas, sendo essas constituídas por muitos compostos sulfatados, geram grande pressão iônica atraindo o sódio e, consequentemente, a água para o tecido cartilaginoso ${ }^{3}$. Portanto a perda de água além de representar a redução da pressão iônica e da hidratação revela ainda perda de proteínas estruturais do tecido cartilaginoso. Essas alterações geram uma importante alteração negativa na capacidade da cartilagem articular de absorver impactos, pois essa propriedade é dependente da integridade estrutural proteica e de sua adequada hidratação ${ }^{6}$.

A imobilização promove redução na atividade dos condrócitos ${ }^{15,16}$, que são os responsáveis pela síntese de proteoglicanas, glicosaminoglicanas, e da matriz extracelular, a qual possui grande quantidade de água. A síntese, assim como a atividade metabólica dos condrócitos, ocorre em resposta ao estímulo mecânico ${ }^{17}$, podendo assim alterar a morfologia e a composição da cartilagem articular. Em seu artigo de revisão Visser et al. ${ }^{13}$, evidenciou que a falta de estímulo mecânico promove atrofia dos condrócitos, reduzindo seu metabolismo, podendo evoluir até o surgimento de erosões na cartilagem articular.

Não foram encontradas diferenças significativas entre os grupos GARL e GARE quando comparados ao GAC. Desta forma podemos sugerir que os processos de estimulação mecânica e mobilização articular gerado pelos protocolos de remobilização induziram ao aumento da atividade dos condrócitos, restabelecendo a condição do tecido aos níveis controle.

Vários experimentos descreveram que o exercício de carga moderada na cartilagem articular gera aumento da síntese e da concentração de proteoglicanas e de glicosaminoglicana ${ }^{18,19}$. Além disso, ele promove aumento do volume da cartilagem e adaptação da mesma ao esforço 20 e estimulando os condrócitos a produzir os elementos que compõem a matriz extracelular ${ }^{13,21,22}$

Del Carlo et al. ${ }^{23}$ realizaram um estudo com ratos imobilizados por 45 dias e remobilizados livre e por meio de exercício físico, no qual os animais que realizaram natação demonstraram quadro menos severo de lesão no tecido cartilaginoso, demonstrada por análise histológica. Chang et al. ${ }^{24}$ evidenciaram que o exercício físico promove uma proteção aos condrócitos mesmo em ratas que foram submetidas à ovariectomia, condição que pode acelerar o processo de degeneração da cartilagem, mantendo assim sua integridade estrutural.

O movimento articular gerado pelo exercício físico facilita a passagem de líquido através da membrana sinovial, aumenta a permeabilidade capilar dos vasos sanguíneos do interstício e altera a pressão intra-articular ${ }^{25}$. Esses fatores associados ao movimento do líquido articular facilitam a entrada de nutriente e a retirada de catabólitos do tecido cartilaginoso, favorecendo o metabolismo dos condrócitos.

O exercício físico realizado no ambiente aquático foi eleito para este estudo, pois a água reduz o impacto gerado pela ação da gravidade, promovendo o movimento articular com menor fricção, facilitando a difusão do líquido sinovial e permitindo o deslizamento das superfícies articulares ${ }^{23}$.

Foi encontrada diferença significativa no conteúdo de água entre os grupos GAC e GIdC, sendo menor no grupo idoso. Pedrinelli et al. ${ }^{26}$ evidenciaram que o processo de senescência diminui a capacidade do organismo de reter água no tecido cartilaginoso, que está associada à diminuição da capacidade de produzir proteoglicanas. No estudo de Caramés et al. ${ }^{27}$ verificou-se que o envelhecimento do tecido cartilaginoso acarreta alterações degenerativas dos condrócitos, com diminuição da síntese dos componentes da matriz, e foi observado também que aparentemente os condrócitos não apresentaram capacidade regenerativa. Em estudo realizado com equinos ${ }^{28}$, o avanço da idade promoveu a diminuição da espessura da cartilagem hialina e do tecido cartilaginoso total, enquanto as espessuras da cartilagem calcificada e do osso subcondral aumentaram.

O envelhecimento cartilaginoso traz consigo um menor poder de agregação dos proteoglicanos, aliado à menor resistência mecânica da cartilagem. O colágeno adquire menor hidratação, maior resistência à colagenase e maior afinidade pelo cálcio ${ }^{29}$.

O processo de senescência promove uma alteração nos condrócitos, reduzindo a produção de proteoglicanas e promovendo alterações estruturais no tecido cartilaginoso e na matriz extracelular, aumentando a probabilidade de ocorrer lesão nesse tecido quando submetido a um estresse ${ }^{30}$. No presente estudo não houve diferença 
entre o grupo GidC e GldRE, o que evidencia que o exercício não promoveu alterações degenerativas no tecido cartilaginoso, mesmo após um protocolo de imobilização.

Dessa forma, o presente estudo colabora com a literatura ao verificar o efeito do processo de imobilização e remobilização na quantidade de água do tecido cartilaginoso de animais adultos e idosos. No entanto, existem limitações a respeito do conteúdo abordado. Estudos futuros, que utilizem técnicas histológicas, bem como formas diferenciadas de exercício físico, podem vir a contribuir com os resultados expostos na presente pesquisa.

\section{CONCLUSÃO}

A imobilização e o processo de senescência induziram a redução do conteúdo de água do tecido cartilaginoso de ratos, e os protocolos de remobilização seja de forma livre ou por meio de exercício físico, foram suficientes para restabelecer este propriedade ao nível de controle nos animais adultos.

Todos os autores declararam não haver qualquer potencial conflito de interesses referente a este artigo.

\section{REFERÊNCIAS}

1. Ando A, Hagiwara $Y$, Tsuchiya M, Onoda Y, Suda H, Chimoto E, et al. Increased expression of metalloproteinase-8 and -13 on articular cartilage in a rat immobilized knee model. Tohoku J Exp Med. 2009:217(4):271-8.

2. Narmoneva DA, Cheung HS, Wang JY, Howell DS, Setton LA. Altered swelling behavior of femoral cartilage following joint immobilization in a canine model. J Orthop Res. 2002;20(1):83-91.

3. Buckwalter JA, Mankin HJ. Instructional course lectures, The American Academy of Orthopaedic Surgeons-articular Cartilage. Part I: Tissue design and chondrocyte-matrix interactions. J Bone Joint Surg Am. 1997;79(4):600-11.

4. Luria A, Chu CR. Articular cartilage changes in maturing athletes: new targets for joint rejuvenation. Sports Health. 2014;6(1):18-30

5. Lee Jl, Sato M, Ushida K, Mochida J. Measurement of diffusion in articular cartilage using fluorescence correlation spectroscopy. BMC Biotechnol. 2011;11:19.

6. Malmonge SM, Zavaglia CAC. Hidrogéis de poliheivia para reparo de defeitos da cartilagem articular. 1- Síntese e caracterização mecânica. Polímeros. 1997;7(2):22-9.

7. Kobayashi-Miura M, Miura T, Osago H, Yamaguchi Y, Aoyama T, Tanabe T, et al. Rat Articular Cartilages Change Their Tissue and Protein Compositions During Perinatal Period. Anat Histol Embryol. 2014 Dec 9. doi: 10.1111/ahe.12165. [Epub ahead of print]

8. Sohár G, Pallagi E, Szabó-Révész P, Tóth K. New thermogravimetric protocol for the investigation of normal and damaged human hyaline cartilage. J Therm Anal Calorim. 2007;89(3):853-6.

9. Camargo Filho JCS. Caracterização da cartilagem articular do joelho de ratos submetidos a esforços de repetição em esteira rolante. Análise histológica, morfométrica e mecânica da cartilagem articular de joelho de ratos submetidos a esforços de repetição [tese]. Campinas: Faculdade de Ciências Médicas da Universidade Estadual de Campinas; 2006

10. Kodama FY, Camargo RC, Job AE, Ozaki GA, Koike TE, Camargo Filho JC. Muscle mechanical properties of adult and older rats submitted to exercise after immobilization. Acta Ortop Bras. 2012;20(4):218-22.

11. Lima SC, Caierão QM, Durigan JLQ, Schwarzenbeck A, Silva CA, Minamoto VB, et al. Curto período de imobilização provoca alterações morfométricas e mecânicas no músculo de rato. Rev Bras Fisioter. 2007;11(4):297-302

12. Polizello JC, Carvalho L C, Freitas FC, Padula N, Shimano AC, Mattiello-Sverzut AC. Propriedades mecanicas do musculo gastrocnemio de ratas, imobilizado e posteriormente submetido a diferentes protocolos de alongamento. Rev Bras Med Esporte. 2009;15(3):195-9.

13. Visser NA, Vankampen GP, Dekoning MH, Vanderkorst JK. The effects of loading on the synthesis of biglycan and decorin in intact mature articular cartilage in vitro. Connect Tissue Res. 1994;30(4):241-50.

14. Yokota H, Leong DJ, Sun HB. Mechanical loading: bone remodeling and cartilage maintenance. Curr Osteoporos Rep. 2011;9(4):237-42.
15. Becerra J, Andrades JA, Guerado E, Zamora-Navas P, López-Puertas JM, Reddi AH. Articular cartilage: structure and regeneration. Tissue Eng Part B Rev. 2010;16(6):617-27.

16. Ando A, Suda H, Hagiwara Y, Onoda Y, Chimoto E, Saijo Y, Itoi E. Reversibility of immobilizationinduced articular cartilage degeneration after remobilization in rat knee joints. Tohoku J Exp Med. 2011;224(2):77-85.

17. Hunter DJ, Eckstein F. Exercise and osteoarthritis. J Anat. 2009;214(2):197-207.

18. Palmoski MJ, Brandt KD. Running inhibits the reversal of atrophic changes in canine knee cartilage after removal of a leg cast. Arthritis Rheum. 1981;24(11):1329-37.

19. Kiviranta I, Tammi M, Jurvelin J, Säämänen AM, Helminen HJ. Moderate running exercise augments glycosaminoglycans and thickness of articular cartilage in the knee joint of young beagle dogs. J Orthop Res. 1988;6(2):188-95.

20. Jones G, Glisson M, Hynes K, Cicuttini F. Sex and site differences in cartilage development: a possible explanation for variations in knee osteoarthritis in later life. Arthritis Rheum. 2000;43(11):2543-9.

21. Egri $D$, Battistella $L R$, Yoshinari NH. A influência da prática de exercícios físicos sobre a cartilagem articular. Rev Bras Reumatol. 1999;39(1):41-44.

22. Maldonado DC, Silva MC, Neto Sel-R, de Souza MR, de Souza RR. The effects of joint immobilization on articular cartilage of the knee in previously exercised rats. J Anat. 2013;222(5):518-25.

23. Del Carlo RJ, Galvão MR, Viloria MIV, Natali AJ, Barbosa ALT, Monteiro BS, et al. Imobilização prolongada e remobilização da articulação fêmoro-tíbio-patelar de ratos: estudo clínico e microscópico. Arq Bras Med Vet Zootec. 2007;59(2):363-70.

24. Chang TK, Huang $\mathrm{CH}$, Huang $\mathrm{CH}$, Chen $\mathrm{HC}$, Cheng $\mathrm{CK}$. The influence of long-term treadmill exercise on bone mass and articular cartilage in ovariectomized rats. BMC Musculoskelet Disord. $2010 ; 11: 185$

25. Fallah Mohammadi M, Hajizadeh Moghaddam A, Mirkarimpur $\mathrm{H}$. The effects of a moderate exercise program on knee osteoarthritis in male wistar rats. Iran J Basic Med Sci. 2013;16(5):683-8.

26. Pedrinelli A, Garcez-Leme LE, Nobre RSA. O efeito da atividade física no aparelho locomotor do idoso. Rev Bras Ortop. 2009;44(2):96-101.

27. Caramés B, Olmer M, Kiosses WB, Lotz M. The relationship of autophagy defects and cartilage damage during joint aging in a mouse model. Arthritis Rheumatol. 2015. Feb 23. doi: 10.1002/art.39073. [Epub ahead of print]

28. Murray RC, Blunden TS, Branch MV, Tranquille CA, Dyson SJ, Parkin TD, et al. Evaluation of age-related changes in the structure of the equine tarsometatarsal osteochondral unit. Am JVet Res. 2009;70(1):30-6.

29. Rossi E. Envelhecimento do sistema osteoarticular. Einstein. 2008;6(Supl 1):7-12.

30. L'Hermette MF, Tourny-Chollet C, Polle G, Dujardin FH. Articular cartilage, degenerative process, and repair: current progress. Int J Sports Med. 2006;27(9):738-44. 